\title{
Los últimos coletazos del viejo sistema español de responsabilidad por daños ambientales
}

\section{The death throes of the old spanish system of liability for environmental damage}

\author{
GERMÁN VALENCIA MARTÍN ${ }^{1}$
}

Resumen: Este trabajo analiza las últimas resoluciones judiciales en el caso de las minas de Aznalcóllar (o caso Boliden). Un suceso bien conocido en España que produjo importantes daños ambientales y que, por ser previo a la nueva Ley de Responsabilidad Medioambiental y tenerse que resolver con arreglo a la legislación anterior, está causando innumerables problemas para obtener el reembolso de los cuantiosos gastos invertidos por las administraciones públicas españolas en la reparación de los daños. Planteado un conflicto negativo de competencia entre las jurisdicciones civil y contencioso-administrativa, la Sala Especial de Conflictos de Competencia del Tribunal Supremo acaba de devolver el conocimiento del asunto a la primera. A juicio del autor, se trata, sin embargo, de un falso o aparente conflicto, provocado por las lagunas de aquella legislación, afortunadamente superada de cara al futuro.

Palabras clave: responsabilidad medioambiental - daños medioambientales minas de Aznalcóllar - Boliden - conflicto negativo de competencia

Summary: This paper analyzes the last judgments in the case of the Aznalcóllar mines (or Boliden case). A well-known event in Spain that produced significant environmental damage, and that, having occurred before the new Law on Environmental Liability and to be resolved under the previous legislation, is causing countless problems for reimbursement of the substantial expenditures invested by the Spanish Public Administration in repairing the damage. Posed a negative conflict of jurisdiction between civil and administrative courts, the Special Chamber of Conflicts of Jurisdiction of the Supreme Court has just returned the matter back to the former. To the author, it is, however, a false or apparent conflict, because of loopholes in that previous law, fortunately overcome for the future.

Key words: environmental liability - environmental damage - Aznalcóllar mines - Boliden - negative conflict of jurisdiction

1 Una versión ligeramente distinta de este trabajo, con el título de «Boliden: un extraño conflicto negativo de competencia», se va a publicar en el número 24 (2013) de la Revista Aranzadi de Derecho Ambiental, actualmente en prensa.

Germán Valencia es profesor titular de Derecho Administrativo de la Universidad de Alicante, España. Correo electrónico: German.Valencia@ua.es 


\section{INTRODUCCIÓN}

Una de las grandes virtudes de la ley 26/2007, de 23 de octubre, de Responsabilidad Medioambiental, de cuya aplicación práctica, por cierto, poco se sabe todavía, es que simplifica e impone racionalidad en el tratamiento de una materia de indudable trascendencia, como es la exigencia de responsabilidades patrimoniales en orden a la reparación de los daños ambientales en sentido estricto (daños a las aguas, a la biodiversidad protegida y contaminación del suelo). La llamada a partir de ahora «responsabilidad medioambiental» contaba hasta entonces en España con una regulación dispersa, insatisfactoria y proclive a provocar numerosos litigios ${ }^{2}$.

En efecto, la mencionada ley, que trae causa de la directiva comunitaria 2004/35/CE, de 21 de abril de 2004, del mismo título, aunque más circunstanciado (sobre responsabilidad medioambiental en relación con la prevención y reparación de daños medioambientales) ${ }^{3}$, objetiva, como era razonable, la responsabilidad medioambiental para las actividades de riesgo, como la implicada en el caso que aquí nos ocupa (la gestión de los residuos de industrias extractivas) e independiza, así, su exigencia (que la ley y la directiva sitúan inicialmente en vía administrativa) de la depuración de cualesquier otras responsabilidades de tipo sancionador, penales o administrativas, en que pudiera haber incurrido el operador causante del daño ${ }^{4}$.

El panorama hasta ese momento no era tan halagüeño. Salvo en el caso de los suelos contaminados (tras la Ley de Residuos de 19985), la legislación española ponía sistemáticamente en relación la responsabilidad por daños ambientales en sentido estricto con la comisión de una infracción, penal (artículo 339 del Código Penal $(\mathrm{CP})^{6}$ ) o al menos administrativa, con las lógicas consecuencias en orden a su caracterización como una responsabilidad cuando menos culposa, y los consiguientes vínculos

2 Ley 26/2007, de 23 de octubre, de Responsabilidad Medioambiental. Boletín Oficial del Estado (BOE), 255, 24 de octubre de 2007. Toda la legislación (tanto española como comunitaria europea) citada en el texto es fácilmente localizable en la página web del Boletín Oficial del Estado (www.boe.es).

3 Directiva 2004/35/CE del Parlamento Europeo y del Consejo, de 21 de abril de 2004, sobre responsabilidad medioambiental en relación con la prevención y reparación de daños medioambientales. Diario Oficial de la Unión Europea (DO), 143, 30 de abril de 2004.

4 Sobre la nueva legislación (comunitaria europea y española) en materia de responsabilidad medioambiental, ver, entre otros: LozAno CutANDA, Blanca (coord.). Comentarios a la Ley de Responsabilidad Medioambiental (Ley 26/2007, de 23 de octubre). Cizur Menor, Navarra: ThomsonCivitas, 2008; ESTEVE PARDO, José. Ley de responsabilidad medioambiental. Comentario sistemático. Madrid/Barcelona/Buenos Aires: Marcial Pons, 2008; RUDA GonzÁLEZ, Albert. El daño ecológico puro. La responsabilidad civil por el deterioro del medio ambiente, con especial atención a la Ley 26/2007, de 23 de octubre, de Responsabilidad Medioambiental. Cizur Menor, Navarra: ThomsonAranzadi, 2008; AUTORES VARIOS. Estudios sobre la Directiva 2004/35/CE, de Responsabilidad por daños ambientales y su incidencia en el ordenamiento español. Cizur Menor, Navarra: ThomsonAranzadi, 2005; y VALENCIA MARTíN, Germán. "La responsabilidad medioambiental». Revista General de Derecho Administrativo, 25 (2010).

5 Ley 10/1998, de 21 de abril, de residuos; hoy sustituida por la ley 22/2011, de 28 de julio, de residuos y suelos contaminados.

6 Ley orgánica 10/1995, de 23 de noviembre, del Código Penal. 
formales con la apertura y desenvolvimiento de los correspondientes procedimientos sancionadores, flexibilizados en ocasiones por alguna legislación sectorial (por ejemplo, la de aguas, que establece un plazo de prescripción de quince años para la obligación de reparar los daños causados al dominio público, artículo 327.1 del Reglamento del Dominio Público Hidráulico $\left.{ }^{7}\right)$, pero, con todo, fuente inagotable de conflictos (ver, por ejemplo, en relación con la propia legislación de aguas, la Sentencia de la Sala de lo Contencioso-Administrativo del Tribunal Supremo de 15 de octubre de $2009^{8}$ ). Y, por su parte, la jurisprudencia civil, que tan eficaz y resueltamente resolvía, con parámetros de responsabilidad objetiva o cuasi objetiva, los problemas resultantes de la producción de daños tradicionales (a las personas o a sus patrimonios) derivados del mismo tipo de incidentes, comprensiblemente se resistía a extender la aplicación de los artículos 1902 y siguientes del Código Civil a la reparación de los daños ambientales en sentido estricto, por esencia de carácter colectivo o difuso, no individualizables en una persona o grupo de personas. En este sentido podemos referirnos, por ejemplo, a las sentencias de la Sala de lo Civil del Tribunal Supremo de 28 de enero de 2004 (FJ 2) y de 14 de marzo de 2005 (FJ 2) ${ }^{9}$ :

La protección del medio ambiente está proclamada en el artículo 45.1 de la Constitución Española, regulada en numerosas normas administrativas y la responsabilidad civil se desprende de las arcaicas previsiones de los números 2o y 4o del artículo 1908 del Código Civil que hablan de humos y emanaciones, pero cuya formulación se extiende a las inmisiones intolerables y a las agresiones al medio ambiente. Esta última puede considerarse en abstracto, como protección al ambiente sano y adecuado para el desarrollo de la persona, y en concreto, como protección específica a derechos subjetivos patrimoniales. La primera no ha sido objeto — difícilmente puede serlo en el ámbito del Derecho civil— de sentencia alguna de esta Sala; la segunda tiene - aunque no siempre se ha indicado explícitamente- una reiterada jurisprudencia civil ${ }^{10}$.

Así pues, el «sistema» español anterior a la nueva ley, compuesto por la legislación y su interpretación y aplicación jurisprudencial que sumariamente acabamos de describir, no solo hacía injustificadamente de peor condición la responsabilidad por los «daños medioambientales»

7 Real decreto 849/1986, de 11 de abril, por el que se aprueba el Reglamento del Dominio Público Hidráulico.

8 La mayor parte de las resoluciones judiciales que se citan en el trabajo son fácilmente localizables a través del buscador de jurisprudencia del Consejo General del Poder Judicial de España (CENDOJ), de acceso libre y gratuito en la página web del mismo (www.poderjudicial.es). Para facilitar la búsqueda, añadiremos, a partir de ahora, a pie de página y para cada resolución su número de la colección (número Roj). En el caso de la presente, Roj: STS 6370/2009.

9 Roj: STS 400/2004 y STS 1556/2005, respectivamente.

10 Las cursivas son nuestras.

LOS ÚLTIMOS

COLETAZOS DEL

VIEJO SISTEMA

ESPAÑOL DE

RESPONSABILIDAD

POR DAÑOS

AMBIENTALES

THE DEATH

THROES OF THE

OLD SPANISH

SYSTEM OF

LIABILITY FOR

ENVIRONMENTAL

DAMAGE 
que la responsabilidad por los daños tradicionales derivados de la misma clase de incidentes (objetiva esta, culpable aquella), y ejercía una presión indebida sobre los mecanismos sancionadores (penales o administrativos) con el fin de obtener consecuencias de tipo reparador o la recuperación de los gastos ya invertidos en la reparación del daño ambiental, que eran, a mi juicio, sus dos principales defectos, sino que además generaba una excesiva litigiosidad sobre cuestiones, por así decirlo, adjetivas (por ejemplo, la prescripción de la infracción) y podía conducir en determinados casos a auténticos callejones sin salida o vacíos de responsabilidad.

Un caso paradigmático de las señaladas deficiencias de este sistema, por la magnitud de los daños ambientales producidos y, por tanto, de las eventuales responsabilidades, y por la interminable y compleja sucesión de actuaciones y pleitos de todo orden a que ha dado lugar con el fin de lograr el reembolso de los fondos públicos invertidos en su reparación, lo constituye el conocido caso de las minas de Aznalcóllar (o caso Boliden). Caso que ha abocado finalmente (por el momento) a un extraño conflicto negativo de competencia entre las jurisdicciones civil y contencioso-administrativa, planteado de acuerdo con las previsiones del artículo 50 de la Ley Orgánica del Poder Judicial $\left(\mathrm{LOPJ}^{11}\right.$ ) y resuelto, de la manera que luego veremos, por tres autos de la Sala Especial de Conflictos de Competencia del Tribunal Supremo (de 26 de abril de 2012, dos de ellos, y el otro de 20 de julio de $2012^{12}$ ), que son los que motivan este pequeño trabajo.

Para una mejor comprensión de los términos del conflicto, de la respuesta dada al mismo por los citados autos y de nuestra valoración de estas decisiones, conviene repasar brevemente los antecedentes más relevantes de la historia judicial del caso Boliden.

\section{PRIMERAS ACTUACIONESEN EL CASO BOLIDEN} Como se recordará, el 25 de abril de 1998 se produjo la rotura de la balsa de decantación de residuos mineros de una explotación de piritas situada en el municipio de Aznalcóllar (provincia de Sevilla), de la que era concesionaria la empresa «Boliden Apirsa, S.L.», filial española de una multinacional sueco-canadiense del sector (Boliden), lo que provocó el vertido de varios millones de metros cúbicos de aguas y lodos tóxicos en la cuenca del río Guadiamar (afluente del Guadalquivir). En las tareas de evitación de daños mayores (contención de la riada para impedir que afectara al Parque Nacional de Doñana) y de reparación de los daños ambientales producidos (descontaminación de las aguas y de los suelos de las márgenes del río Guadiamar, hoy convertido en 
un espacio natural protegido, el «Corredor verde» del mencionado río), las administraciones competentes (estatal y autonómica) invirtieron considerables sumas de dinero, que lógicamente se propusieron luego recuperar de la empresa titular de la explotación ${ }^{13}$.

Se procedió, primero, como es normal ante unos hechos de tanta trascendencia, por la vía penal, mediante la apertura de diligencias previas por el Juzgado de Instrucción número dos de Sanlúcar la Mayor (Sevilla), que, no obstante, fueron tempranamente archivadas (por auto de 22 de diciembre de 2000), al entender los tribunales penales (la decisión de archivo fue confirmada en apelación) que en la actuación de las distintas personas imputadas no concurría la «imprudencia grave» que, como mínimo, es necesaria para apreciar la existencia de delito ecológico (artículo $331 \mathrm{CP}$ ).

Archivada la causa penal, la Confederación Hidrográfica del Guadalquivir reanudó la tramitación del expediente sancionador que había iniciado en paralelo contra «Bolidén Apirsa, S.L.», que concluyó por Acuerdo del Consejo de Ministros de 2 de agosto de 2002, en el que, junto a la máxima sanción entonces prevista para las infracciones muy graves en la legislación de aguas (la apreciada fue la tipificada en el artículo 108, letras f) y g) de la Ley de Aguas de 1985, hoy artículo 116.3, letras f) y g) del Texto Refundido de $2001^{14}$ ), esto es, una multa de 601 012,10 euros, se ordenaba a la empresa el reembolso de los costes en que había incurrido la administración estatal en la reparación del daño («reposición de las cosas a su estado anterior», artículo 110.1 de la Ley de Aguas, hoy artículo 118.1 del Texto Refundido), por importe de más de cuarenta y un millones de euros. Tanto la sanción como la obligación de reembolso (con una pequeña rebaja en su cuantía) fueron confirmadas por sentencia de la Sala de lo Contencioso-Administrativo del Tribunal Supremo de 22 de noviembre de $2004^{15}$, por entender que en la actuación de la empresa sí hubo, al menos, el grado de culpa suficiente para calificar los hechos como infracción administrativa e imponer las consiguientes obligaciones de reparación.

El Estado no ha hecho todavía efectivas esas cantidades, pues Boliden Apirsa, S.L. quedó rápidamente descapitalizada, entrando en suspensión de pagos y en proceso de liquidación, pero al menos la administración estatal cuenta con un título, confirmado por sentencia judicial firme, que legitima su posición acreedora en el expediente

13 Sobre el suceso de Aznalcóllar, con más detalles, ver, entre otros: GARRIDO, Héctor (coord.). Guadiamar, ciencia, técnica y restauración. El accidente minero diez años después. Madrid: Consejo Superior de Investigaciones Científicas (CSIC), 2008.

14 Ley 29/1985, de 2 de agosto, de Aguas; hoy vigente como Texto Refundido de la Ley de Aguas, aprobado por real decreto legislativo 1/2001, de 20 de julio.

15 Roj: STS 7562/2004.

LOS ÚLTIMOS

COLETAZOS DEL VIEJO SISTEMA

ESPAÑOL DE

RESPONSABILIDAD

POR DAÑOS

AMBIENTALES

THE DEATH

THROES OF THE

OLD SPANISH

SYSTEM OF

LIABILITY FOR

ENVIRONMENTAL

DAMAGE 
concursal (concurso voluntario de acreedores) que se sigue todavía frente a la empresa ante el Juzgado de lo Mercantil número uno de Sevilla, y al que volveremos a hacer referencia más tarde.

\section{LA VÍA CIVIL}

Mucho más azarosa (y todavía precaria) fue la situación de la Junta de Andalucía, que también incurrió en considerables gastos en las tareas de reparación de los daños producidos por el suceso de Aznalcóllar (unos noventa millones de euros), y que, en parte a causa de las actuaciones ya comentadas, se vio conducida a una interminable e infructuosa sucesión de pleitos, que han desembocado en los autos objeto de comentario (de cuyos antecedentes extraemos algunos de los datos que a continuación se exponen).

En efecto, cerradas para la Junta de Andalucía las vías ordinarias entonces previstas en nuestro ordenamiento para la exigencia de responsabilidad por daños ambientales (en este caso, para la recuperación de los costes soportados en virtud de lo que la nueva ley denomina «actuación directa»), esto es, la vía penal, por el archivo de las diligencias previas, y la sancionadora administrativa, por la sanción ya impuesta por la administración estatal en el marco de la legislación de aguas, que no incluyó los desembolsos efectuados por la Junta, esta buscó otros caminos.

Muy honestamente, la Junta de Andalucía no intentó forzar las cosas, abriendo un expediente sancionador por la posible comisión de una infracción en el ámbito de sus competencias (la legislación de minas), que no creía se hubiera cometido, inclinándose en su lugar por la vía civil. Así lo ponen de manifiesto sus palabras en la apelación del juicio civil, que luego transcribirían las sentencias de la ulterior vía contencioso-administrativa (de donde las tomamos), y que concuerdan con la descripción general del panorama normativo entonces existente que antes hicimos:

Es evidente que si la Administración Andaluza ha acudido a los órganos jurisdiccionales del orden civil en ejercicio de una acción puramente civil de reembolso o reintegro de gastos, es porque carecía de potestades de autotutela para reintegrarse de los gastos que subsidiariamente ha asumido [de] quién venía obligado a ello, el concesionario minero, como claramente prevé el art. 81 de la Ley de Minas [...] Así las cosas, y dado que en el seno de la relación que liga a esta Administración con el concesionario en virtud de la concesión minera, regulada por normas administrativas, la Administración concedente no ha constatado existencia de incumplimientos del régimen de la concesión por parte del concesionario, ningún precepto legal le habilita en este ámbito 
para declarar administrativamente la existencia de esa obligación y su alcance cuantitativo so pena de incurrir en vía de hecho ${ }^{16}$.

En efecto, el 16 de noviembre de 2002, la Junta de Andalucía presentó demanda civil, en juicio ordinario, dirigida no solo contra Boliden Apirsa S.L., sino también solidariamente contra la matriz (Boliden $\mathrm{AB}$ ) y otra empresa del grupo (Boliden BV), reclamando la cantidad ya mencionada por los gastos soportados (concretamente, por los gastos derivados de la «retirada de lodos, depuración de aguas, inmovilización química de metales pesados, control de calidad ambiental, investigación científica, restauración ecológica de la zona y control sanitario»), y fundada en el derecho de repetición de quien efectúa un pago por tercero, reconocido en el artículo 1158 del Código Civil («El que pagare por cuenta de otro podrá reclamar del deudor lo que hubiese pagado»), en relación con el artículo 1908 del mismo (responsabilidad civil extracontractual por inmisiones, de cariz objetivo).

Sin embargo, en coherencia con la posición antes comentada de la jurisprudencia civil española sobre la aplicación del instituto de la responsabilidad civil extracontractual a los daños ambientales en sentido estricto, la demanda fue inadmitida por auto del Juzgado de Primera Instancia número once de Sevilla de 28 de diciembre de 2002, luego confirmado en apelación por auto de la Audiencia Provincial de Sevilla (sección sexta) de 2 de octubre de $2003^{17}$, por el motivo de «falta de jurisdicción» («por no tener competencia jurisdiccional este juzgado para conocer de la misma»), con indicación (como impone el artículo 9.6 LOPJ) de la jurisdicción considerada competente («correspondiendo a la Administración resolver sobre la misma, con posibilidad de acudir posteriormente a la Jurisdicción Contencioso-Administrativa»).

Fuera o no lo más indicado inadmitir la demanda (en lugar de desestimarla, lo que tal vez hubiera evitado el conflicto), el razonamiento de estas resoluciones encerraba, a mi juicio, una lógica evidente dentro del contexto jurisprudencial ya conocido sobre el alcance de la responsabilidad civil extracontractual, pues el reconocimiento del derecho de repetición en favor de quien ha pagado la «deuda» de otro tiene obviamente como presupuesto la posibilidad de conocer y determinar la existencia y el alcance de dicha «deuda». Esto es lo que, en este caso, por la propia naturaleza de la obligación (responsabilidad medioambiental), los tribunales entendieron que caía fuera de su jurisdicción. Así lo ponía de manifiesto el auto dictado en apelación por la Audiencia Provincial de Sevilla (FJ 1):

LOS ÚLTIMOS

COLETAZOS DEL

VIEJO SISTEMA

ESPAÑOL DE

RESPONSABILIDAD

POR DAÑOS

AMBIENTALES

THE DEATH

THROES OF THE

OLD SPANISH

SYSTEM OF

LIABILITY FOR

ENVIRONMENTAL

DAMAGE 
Pero este derecho de repetición por el desembolso efectuado exige que las empresas Boliden sean consideradas como deudoras o personas obligadas a reintegrar las cantidades pagadas por la Junta de Andalucía. Y presupuesto necesario para que las empresas Boliden sean consideradas como deudoras de esta obligación, es que sean consideradas como responsable[s] de los daños ambientales producidos por la rotura de la balsa, no siendo la jurisdicción civil la competente para enjuiciar si se ha[n] producido estos daños ambientales y la obligación de reponer las cosas a su estado anterior, correspondiendo tal conocimiento a la Jurisdicción ContenciosoAdministrativa, dado que las relaciones derivadas entre la Junta y las empresas Boliden se configuran dentro de la concesión administrativa, máxime cuando los pretendidos daños ambientales podrían haber sido ocasionados por personas diferentes a las Empresas Boliden.

\section{LA VÍA ADMINISTRATIVA Y CONTENCIOSO- ADMINISTRATIVA}

Cerrada, pues, también (de momento) la vía civil, y siguiendo las indicaciones de los referidos autos de inadmisión, la Junta inició seguidamente, aunque sin mucha convicción, la vía administrativa. En coherencia con su visión de las cosas, interpuso también en paralelo un recurso de amparo frente a dichos autos, que le cerraban la vía considerada por ella pertinente, por supuesta vulneración del derecho a la tutela judicial efectiva, pero que sería inadmitido por el Tribunal Constitucional por prematuro, por resolución de 14 de febrero de 2005.

En efecto, la Junta de Andalucía (por orden de 10 de noviembre de 2003) abrió un expediente administrativo de carácter no sancionador, encaminado única y exclusivamente a depurar la responsabilidad patrimonial de las empresas Boliden, al amparo de la legislación de su competencia ejecutiva (la minera), concretamente con base en el artículo 81 de la Ley de Minas de $1973^{18}$,que concluyó con resolución del Consejo de Gobierno de la Junta de Andalucía de 23 de marzo de 2004, por la que se declaraba la obligación solidaria de las empresas del Grupo de reembolsar a la Junta la cantidad ya conocida.

Las tres empresas interpusieron por separado sendos recursos contencioso-administrativos contra la indicada resolución, lo que explica que a partir de ahora (incluida la resolución de los conflictos

18 Ley 22/1973, de 21 de julio, de Minas: «Todo titular o poseedor de derechos mineros reconocidos en esta Ley será responsable de los daños y perjuicios que ocasione con sus trabajos, así como de los producidos a aprovechamientos colindantes por intrusión de labores, acumulación de agua, invasión de gases y otras causas similares y de las infracciones que cometa de las prescripciones establecidas en el momento del otorgamiento para la protección del medio ambiente, que se sancionarán en la forma que señale el Reglamento, pudiendo llegarse a la caducidad por causa de infracción grave». 
negativos de competencia de que luego hablaremos) existan siempre, en relación con este caso, tres resoluciones judiciales distintas, aunque del mismo tenor.

La Sala de lo Contencioso-Administrativo del Tribunal Superior de Justicia de Andalucía (sección primera, con sede en Sevilla), que conoció del asunto en primera instancia (técnicamente en única), estimó los recursos por sentencias de 2 de noviembre (Boliden AB) y 17 de diciembre (Boliden Apirsa S.L.) de 2007 y de 25 de noviembre de 2008 (Boliden BV), anulando la resolución «por falta de competencia de la Administración para su dictado», y declarando, además, en todas ellas, la «incompetencia de la jurisdicción contencioso-administrativa para el pronunciamiento respecto de la acción de reembolso ejercitada [por la Junta de Andalucía, obviamente, no por los recurrentes]», e invitando a esta («teniendo en cuenta que la jurisdicción civil, que estimamos competente, ha efectuado declaración de incompetencia de jurisdicción», como ya nos consta), a plantear un conflicto negativo de competencias entre jurisdicciones, conforme las previsiones del artículo 50 LOPJ (a «acudir al procedimiento del recurso por defecto de jurisdicción, regulado en el art. 50 LOPJ») ${ }^{19}$.

Teniendo en cuenta los antecedentes del caso, no resulta extraño que las indicadas sentencias comiencen examinando, como cuestión previa, la relativa a la competencia de la jurisdicción contencioso-administrativa para conocer del asunto.

A este respecto, y en contra del parecer del Ministerio Fiscal (que desde el pleito civil hasta la resolución del conflicto negativo de competencia, defendió siempre la competencia de la jurisdicción civil), las sentencias (FJ 2) afirman, razonablemente, la competencia de la jurisdicción contencioso-administrativa para examinar la legalidad de un acto que, al menos «formalmente», se presenta como un acto administrativo, supuestamente amparado en el ejercicio de una potestad administrativa, es decir, para examinar la existencia o no de esa potestad, cuestionada por las empresas recurrentes.

Y entrando, pues, en esta cuestión, las sentencias (FJ 3) concluyen, de forma también razonable, que, de acuerdo con la legislación aplicable al caso (y a diferencia de la nueva Ley de Responsabilidad Medioambiental, que también se cita a efectos de contraste), la administración andaluza carecía de potestad de autotutela para obtener en vía administrativa el reembolso de las cantidades invertidas en la reparación de los daños, como, por lo demás, había reconocido la Junta de Andalucía en el pleito civil, a través de las palabras que antes hemos reproducido, y que las sentencias citan literalmente.

LOS ÚLTIMOS COLETAZOS DEL VIEJO SISTEMA ESPAÑOL DE RESPONSABILIDAD POR DAÑOS AMBIENTALES

THE DEATH THROES OF THE OLD SPANISH SYSTEM OF LIABILITY FOR ENVIRONMENTAL DAMAGE 
No le brindaba, en primer término, dicha potestad el artículo 81 de la Ley de Minas, invocado por la resolución impugnada, cuyo primer inciso ${ }^{20}$, único examinado, contiene simplemente, a juicio de las sentencias, la regla habitual de reparto o asignación de responsabilidades por daños a terceros entre la administración y el concesionario, pero sin atribuir a la administración autotutela alguna para su exigencia:

El precepto trascrito, al contrario de lo que se afirma, no otorga competencia de autotutela alguna a la Administración para resarcirse de los gastos y costes que se reclaman en el Acuerdo impugnado. Dicho precepto únicamente contiene una referencia a la responsabilidad del titular o poseedor de los derechos mineros, de modo que los terceros perjudicados puedan exigir la responsabilidad al titular, mediante el ejercicio de las oportunas acciones judiciales, esto es, lo que hace es dejar claro que la responsabilidad para la reparación de los daños corresponde al titular de la explotación y no a la Administración que otorgó la correspondiente concesión minera. En ningún caso, puede entenderse que por dicho precepto se otorgue competencia a la Administración para exigir, sin necesidad de acudir a los tribunales de justicia, el reintegro de los daños sufridos, sino al contrario, tiene por finalidad esclarecer que los terceros perjudicados han de reclamar los daños al titular de la explotación y no a la Administración.

Y, en segundo lugar, tampoco cabía derivar esa potestad de autotutela del artículo 1158, en relación con el artículo 1908, ambos del Código Civil, también invocado por la Junta en su contestación a la demanda como fundamento de la resolución, pues obviamente «dichos preceptos del derecho privado, en ningún caso, pueden otorgar a la Administración competencias de autotutela, no siendo posible la utilización de procedimientos administrativos para el ejercicio de acciones civiles».

Estos sencillos razonamientos sirven, pues, al Tribunal Superior de Justicia para tomar la primera de sus decisiones, la de anular la resolución impugnada «por falta de competencia» (o, mejor, de potestad) de la administración (FJ 3 in fine):

En definitiva, no existía precepto legal alguno, en la fecha del dictado de la resolución, que otorgara a la Administración habilitación para

20 «Todo titular o poseedor de derechos mineros reconocidos en esta Ley será responsable de los daños y perjuicios que ocasione con sus trabajos, así como de los producidos a aprovechamientos colindantes por intrusión de labores, acumulación de agua, invasión de gases y otras causas similares». 
reclamar mediante un procedimiento administrativo la reparación de unos daños amparados en un título de derecho privado; debiéndose entender que el modo de proceder de la Administración se encuentra motivado, como consecuencia de haber quedado cegada la posibilidad de acceso a la vía jurisdiccional civil, como se reconoce en el propio Acuerdo impugnado, por lo que ha de estimarse el recurso y anularse la actuación administrativa formal tendente a intentar reintegrarse de los gastos satisfechos.

Entre paréntesis, cabe añadir que las sentencias no se plantean como posible fundamento de la exigencia de reparación (reembolso, en este caso) la potestad sancionadora de la administración, a la que también alude el segundo inciso del artículo 81 de la Ley de Minas ${ }^{21}$, en relación con los preceptos de otras leyes que, con carácter general, imponen al «infractor» la obligación de reparar el daño causado (artículo 130.2 de la Ley de Régimen Jurídico de las Administraciones Públicas y del Procedimiento Administrativo Común (LRJPAC): «Las responsabilidades administrativas que se deriven del procedimiento sancionador serán compatibles con la exigencia al infractor de la reposición de la situación alterada por el mismo a su estado originario, así como con la indemnización por los daños y perjuicios causados» ${ }^{22}$ ), porque, como sabemos, la resolución no tenía carácter sancionador y la Junta tampoco lo adujo en su contestación a la demanda. Ni se plantean, por tanto, como ha hecho la jurisprudencia en otros contextos normativos (de los que luego hablaremos), la posible pervivencia de la acción administrativa de reparación una vez prescrita la infracción ni cuál sería en este caso su plazo de ejercicio, sino que, examinando el asunto en los términos sugeridos por la Junta, se limita a constatar, como ya hemos visto, que ninguno de los dos títulos invocados legitimaban en este caso la actuación de la administración en vía administrativa.

Tal vez las sentencias podrían haberse detenido ahí, en la anulación de la resolución impugnada. Pero es claro que para el Tribunal Superior de Justicia está sola respuesta resultaba insatisfactoria, al dejar imprejuzgada la cuestión de fondo que planteaba, no tanto el recurso contenciosoadministrativo como el caso en sí mismo, es decir, la pretensión de la Junta de Andalucía de reembolso. Y como, de acuerdo con el parecer de la propia Junta, el fundamento de dicha pretensión se encontraba en los artículos 1908 y 1158 del Código Civil, a continuación las sentencias

21 «Todo titular o poseedor de derechos mineros reconocidos en esta Ley será responsable [...] de las infracciones que cometa de las prescripciones establecidas en el momento del otorgamiento para la protección del medio ambiente, que se sancionarán en la forma que señale el Reglamento, pudiendo llegarse a la caducidad por causa de infracción grave».

22 Ley 30/1992, de 26 de noviembre, de Régimen Jurídico de las Administraciones Públicas y del Procedimiento Administrativo Común.

LOS ÚLTIMOS

COLETAZOS DEL

VIEJO SISTEMA

ESPAÑOL DE

RESPONSABILIDAD

POR DAÑOS

AMBIENTALES

THE DEATH

THROES OF THE

OLD SPANISH

SYSTEM OF

LIABILITY FOR

ENVIRONMENTAL

DAMAGE 
(FJ 4) declaran la incompetencia de la jurisdicción contenciosoadministrativa para conocer de dicha pretensión, para la que consideran competente a la jurisdicción civil, invitando a la Junta, como ya hemos visto y por las razones que ya conocemos, a plantear un conflicto negativo de competencia por defecto de jurisdicción al amparo del artículo 50 LOPJ:

No obstante hemos de señalar, que el conocimiento del asunto se ha limitado al enjuiciamiento del acto impugnado en cuanto ejercicio de autotutela de la Administración. Dado que el Letrado de la Junta de Andalucía en la contestación a la demanda, sostiene que el título de imputación de la obligación respecto de la actora [...] se encuadra en el derecho privado por imperativo del art. 1908 del Código Civil en cuanto verdadero propietario, y hallándonos ante un supuesto de pago por tercero del art. 1158 Código Civil, esta Sala no puede efectuar un pronunciamiento en cuanto a la acción civil ex art. 1908 del Código Civil ejercitada por la Administración, conforme prevén los arts. 9 LOPJ y 1 de la Ley reguladora de esta Jurisdicción, pues la procedencia de la reclamación basada en el Derecho Civil es ajena a la competencia de esta Jurisdicción. Y teniendo en cuenta que la jurisdicción civil, que estimamos competente, ha efectuado declaración de incompetencia de jurisdicción, las partes habrán de acudir al procedimiento del recurso por defecto de jurisdicción, regulado en el art. 50 de la $\mathrm{LOPJ}^{23}$.

Antes de plantear el «recurso por defecto de jurisdicción», y dado que el artículo 50.1 LOPJ exige la firmeza de la resolución que provoca el conflicto («Contra la resolución firme en que el órgano del orden jurisdiccional $[. .$.$] declare su falta de jurisdicción en un proceso cuyos$ sujetos y pretensiones fuesen los mismos...»), la Junta de Andalucía interpuso los correspondientes recursos de casación contra las indicadas sentencias, que fueron resueltos por sentencias de la Sala de lo Contencioso-Administrativo del Tribunal Supremo (sección quinta) de fechas 10 de noviembre de 2011 (Boliden Apirsa S.L.), la primera de ellas, y 11 de noviembre de 2011, las otras dos (Boliden AB y Boliden BV) ${ }^{24}$.

Las sentencias del Tribunal Supremo confirman en todos sus extremos las anteriores del Tribunal Superior de Justicia, tanto en lo relativo a la anulación de la resolución de la Junta por falta de potestad, como en lo referente a la incompetencia de la jurisdicción 
contencioso-administrativa para conocer de la pretensión de reembolso de la Junta, sin añadir nuevos argumentos de relieve. Lamentan, eso sí, por lo que a la segunda de las cuestiones se refiere, el «peregrinaje judicial» al que se habría visto sometida la Junta (FJ 6), pero haciéndola en parte responsable del mismo, por no haber planteado el conflicto negativo de competencia inmediatamente a continuación de aquellas y haber optado, en su lugar, por interponer los recursos de casación ${ }^{25}$; reproche tal vez inmerecido, a la vista del tenor literal del artículo 50 LOPJ, antes transcrito.

\section{EL CONFLICTO NEGATIVO DE COMPETENCIA}

Tras la desestimación de los recursos de casación, la Junta de Andalucía formalizó el conflicto, mediante la interposición (en diciembre de 2011), como manda el artículo 50 LOPJ, de un «recurso por defecto de jurisdicción» ante el órgano que declaró en segundo lugar su falta de jurisdicción, esto es, ante la Sala de lo Contencioso-Administrativo del Tribunal Superior de Justicia de Andalucía.

De acuerdo con la LOPJ (artículo 42), los «conflictos de competencia» (que así se llaman cuando se traban entre distintos órdenes jurisdiccionales, frente a las expresiones «cuestiones de competencia», utilizada para los conflictos entre tribunales de un mismo orden jurisdiccional, y «conflictos de jurisdicción», reservada para los planteados entre administración y tribunales o entre jurisdicción ordinaria y militar) los resuelve una Sala Especial del Tribunal Supremo (la «Sala Especial de Conflictos de Competencia») compuesta por el presidente y dos magistrados del Tribunal Supremo, uno por cada orden jurisdiccional en conflicto.

El conflicto quedó formalizado entre los dos tribunales que habían declinado de inicio su jurisdicción, esto es, el Juzgado de Primera Instancia número once de Sevilla y la Sala de lo Contencioso-Administrativo del Tribunal Superior de Justicia de Andalucía (sección primera, con sede en Sevilla) y, conforme a las previsiones de la LOPJ (artículo 50), una vez recibidas las actuaciones por parte de ambos, la Sala Especial de Conflictos oyó el parecer del Ministerio Fiscal y resolvió por medio de auto. Los autos de la Sala Especial resolutorios de este conflicto son los de fecha 26 de abril de 2012, dos de ellos (Boliden AB y Boliden BV) y 20 de julio de 2012, el tercero (Boliden Apirsa, S.L.), todos del mismo tenor, y que, de acuerdo con el parecer del Ministerio Fiscal (cuyo informe aparece íntegramente transcrito en las resoluciones),

25 FJ 2, in fine: «Si dicha Administración hubiese procedido en la forma señalada por la Sala de instancia cuando le fueron notificadas las sentencias pronunciadas por esta, entre ellas la que ahora es objeto de este recurso de casación, el conflicto de competencia negativo ya estaría resuelto hace tiempo, aunque no se le puede negar su derecho a plantear en casación las infracciones que atribuye a la sentencia recurrida, que, como seguidamente explicaremos brevemente, son inexistentes».

LOS ÚLTIMOS

COLETAZOS DEL

VIEJO SISTEMA

ESPAÑOL DE

RESPONSABILIDAD

POR DAÑOS

AMBIENTALES

THE DEATH

THROES OF THE

OLD SPANISH

SYSTEM OF

LIABILITY FOR

ENVIRONMENTAL

DAMAGE 
resuelven el conflicto en favor dela jurisdicción civil, declarando, pues, la competencia para resolver del Juzgado de Primera Instancia número once de Sevilla ${ }^{26}$.

Los autos (FJ 1) rechazan, en primer término, los dos motivos de inadmisibilidad del conflicto de competencia invocados por las empresas Boliden. En primer lugar, que se tratara en todo caso de un conflicto de jurisdicción, entre tribunales y Administración, a la que reenviaba el primer auto del Juzgado, porque «si bien se pudo plantear en su momento un conflicto de jurisdicción, ello no obsta a que residenciado el conflicto, con posterioridad, entre dos jurisdicciones se pueda plantear el recurso por defecto de jurisdicción conforme al art. 42 de la LOPJ». Y, en segundo lugar, que los «sujetos y pretensiones» de los dos pleitos, el civil y el contencioso-administrativo, no fueran «los mismos» (como exige el artículo 50.1 LOPJ), porque en el fondo sí lo eran, aunque obviamente con inversión de las posiciones procesales en el contencioso-administrativo, lamentando de nuevo la Sala el «peregrinaje judicial» a que se vio sometida la Junta:

El hecho de que no accionara la Junta ante los Juzgados de lo contencioso administrativo (sic), y abriese expediente de autotutela, nada obstaculiza al actual conflicto de competencia, pues tras el indeseable peregrinaje sufrido, el debate se centra en resoluciones de dos jurisdicciones que respectivamente se declaran incompetentes que es el supuesto típico regulado en el art. 42 de la LOPj ${ }^{27}$.

Y, entrando ya en el fondo del conflicto, los autos (FJ 2) consideran que la titularidad de la competencia controvertida corresponde a la jurisdicción civil (devolviendo, pues, el conocimiento del caso al Juzgado de Primera Instancia), por el sencillo argumento (compartido con el fiscal y también, como vimos, por la propia Junta y los tribunales de lo contencioso-administrativo, a los que dan la razón) de que la pretensión inicial que dio origen a este asunto, y que, a su juicio, ha quedado todavía «imprejuzgada», la acción de reembolso ejercitada por la Junta con base en los artículos 1908 y 1158 CC es, como es obvio, una pretensión civil, una reclamación de cantidad frente a sujetos privados y no un supuesto de responsabilidad patrimonial de la Administración:

La naturaleza de la acción ejercitada por su contenido esencial, sus sujetos pasivos y por la normativa que la regula es de encuadramiento dentro del orden del derecho civil y por ello se interpuso la demanda, en su día, ante los Juzgados de Primera Instancia de 
Sevilla viéndose abocada la Junta al itinerario administrativo y contencioso administrativo por imperativo de lo resuelto por el Juzgado y la Audiencia Provincial, siendo preciso que en esta sede se dé una respuesta coherente con el derecho a la tutela judicial efectiva, establecido en el art. 24 de la Constitución, con el fin de evitar que quede imprejuzgada una acción, por causa ajena a la voluntad del demandante 28 .

\section{VALORACIÓN Y CONCLUSIONES}

En otro lugar, he titulado este trabajo como un «extraño» conflicto negativo de competencia, porque, aunque ciertamente el conflicto está bien trabado, posiblemente no había razones para no admitirlo $y$, teniendo que resolverlo, tal vez no cupiera otra respuesta que la dada por la Sala de Conflictos. A pesar de todo ello, y en mi opinión, no deja de ser un conflicto más bien «aparente» o «falso», que las dos jurisdicciones hubieran podido evitar si, en lugar de reenviarse mutuamente el conocimiento del asunto, se hubieran limitado a desestimar las pretensiones de Junta (en el caso de la jurisdicción contencioso-administrativa, a estimar los recursos presentados por la empresa Boliden), como, a mi juicio, podían haber hecho, pues el problema no era tanto cuál de las dos debía conocer de la pretensión, como que la pretensión de la Junta, en los términos en que fue formulada ante una y otra, era tal vez inviable, por las carencias de la legislación aplicable al caso ${ }^{29}$.

Ciertamente, el conflicto está formalmente bien trabado. Dos tribunales de jurisdicciones distintas se declaran incompetentes para conocer de una determinada pretensión (la reclamación económica de la Junta de Andalucía frente a las empresas del grupo Boliden) y los dos apelan recíprocamente a la competencia del otro. Es más, el segundo de ellos señala expresamente a la Junta el camino del conflicto de competencia. Sin embargo, para que exista un verdadero conflicto negativo de competencia o, mejor dicho, para que la solución del mismo consista en la atribución de la competencia controvertida a uno de los dos tribunales que la rechazan, probablemente lo anterior no sea suficiente, porque no cabe descartar que ninguno de los dos sea realmente competente para conocer de la pretensión, al menos, en los términos en que ha sido planteada.

Algo de esto es, en realidad, lo que, a mi juicio, ocurre en el caso presente. La Sala Especial de Conflictos de Competencia del Tribunal Supremo ha

LOS ÚLTIMOS

COLETAZOS DEL

VIEJO SISTEMA

ESPAÑOL DE

RESPONSABILIDAD

POR DAÑOS

AMBIENTALES

THE DEATH

THROES OF THE

OLD SPANISH

SYSTEM OF

LIABILITY FOR

ENVIRONMENTAL

DAMAGE 
considerado que la pretensión es civil, se ha lamentado del «peregrinaje judicial» al que se ha visto sometida la Junta de Andalucía desde la inadmisión de su demanda, y ha devuelto el conocimiento del asunto al Juzgado de Primera Instancia ante el que se planteó por primera vez. Pero no es fácil imaginar qué otra decisión puede tomar ahora, diez años después, el Juzgado de Primera Instancia número once de Sevilla que no sea la de transformar aquella «inadmisión» en una «desestimación» de la demanda, prácticamente con los mismos argumentos de entonces, cuidándose, por supuesto, de no invocar la competencia de otros órganos o jurisdicciones (como, tal vez, podría haberse hecho desde un principio). Con ello podría pensarse que se satisface por fin el «derecho a la tutela judicial efectiva» de la Junta, presuntamente maltrecho hasta ahora, pero no sería una satisfacción «materialmente» muy distinta a la que obtuvo en su momento, con una decisión de inadmisión fundada en derecho.

En efecto, el quid de la cuestión radica, a mi juicio, en el deficiente tratamiento que recibía en el derecho español la «responsabilidad medioambiental» hasta la entrada en vigor de la nueva ley, al que nos referimos en la introducción, que podía generar auténticos callejones sin salida, es decir, convertir en inviables determinadas pretensiones en principio legítimas.

La pretensión «civil» de la Junta estaba quizás condenada al fracaso, porque la jurisprudencia civil española no ha estimado nunca procedente trascender el alcance individualista de la responsabilidad civil extracontractual, circunscribiendo esta institución (sin perjuicio de su objetivación para las actividades de riesgo, al amparo del artículo 1908, o simplemente del artículo 1902) a la reparación de daños individualizables a las personas o sus patrimonios (los llamados daños tradicionales), sin extenderla a la reparación de daños colectivos o difusos, como por definición son los ambientales en sentido estricto, como muestran las sentencias que mencionamos en la introducción y otras posteriores que reafirman la misma idea, como, por ejemplo, la sentencia de la Sala Civil del Tribunal Supremo de 22 de diciembre de 2008 -ERCROS- $(\mathrm{FJ} 4)^{30}$ :

Según declara la STS 14 de marzo de 2005 [...], la protección del medio ambiente y la responsabilidad en que incurre quien lo menoscaba como bien de la colectividad difícilmente puede ser objeto de consideración en el ámbito del Derecho civil. Solo un aspecto de la protección del medio ambiente, el que se refiere a la protección específica de derechos subjetivos patrimoniales, ha 
sido objeto de una reiterada jurisprudencia civil, que contempla, sustancialmente, inmisiones en fincas o propiedades vecinas.

El hecho de que la Junta hubiera procedido directamente a la reparación de los daños y presentara ahora su pretensión como una acción de reembolso (al amparo del artículo $1158 \mathrm{CC}$ ), no cambia mucho las cosas, pues no altera la auténtica naturaleza de los daños ni los convierte, pues, en daños tradicionales o individualizables.

Esa misma pretensión de la Junta de recuperación de costes, canalizada en vía administrativa, hubiera tenido más posibilidades de éxito de haberse vinculado a la comisión de una infracción, como ocurrió en el caso de la administración del Estado, pero difícilmente al margen de tal vínculo. Tal vez el Estado, al castigar la infracción a la legislación de aguas, podría haber incluido los costes soportados por la Junta de Andalucía, o al menos parte de ellos. Quizás también, con más picardía, la Junta podría haber forzado la apertura de un expediente sancionador al amparo de la legislación minera y haber provocado el debate habitual en otros contextos normativos sobre la «independencia» o no de la obligación del «infractor» de reponer las cosas a su estado anterior e indemnizar los perjuicios causados, si no en el plano de la «culpabilidad», sí al menos en el del plazo para el ejercicio de la acción administrativa, más allá de la prescripción de la infracción.

Ver, como ejemplo de estos continuos debates, propiciados por el contexto normativo anterior, la muy reciente sentencia de la Sala de lo Contencioso-Administrativo del Tribunal Superior de Justicia de la Comunidad Valenciana 4/2013, de 8 de enero (DOGV número 6954, de 30 de enero de 2013), dictada en un recurso de casación en interés de ley, a propósito del artículo 55 de la ley 11/1994, de 27 de diciembre, de Espacios Naturales Protegidos de la Comunidad Valenciana, que sienta como doctrina legal y con respeto de la situación jurídica particular derivada de la sentencia recurrida, que «es ajustad[o] a derecho el que la reparación del daño medioambiental causado y la reposición de las cosas a su estado original, prevista en el artículo 55 de la Ley11/1994, de la Generalitat Valenciana, podrá exigirse aun cuando haya prescrito la infracción de la que derivan estas obligaciones», considerando aplicable, «ante el silencio del legislador», el plazo general de quince años que establece el artículo 1964 del Código Civil para las acciones personales que no tienen señalado término especial de prescripción (FJ 2).

Pero las cosas no se plantearon (o no pudieron plantearse) de esta manera, conduciendo también al fracaso de la pretensión de reembolso en vía administrativa. La vieja legislación presentaba estas lagunas,

LOS ÚLTIMOS

COLETAZOS DEL

VIEJO SISTEMA

ESPAÑOL DE

RESPONSABILIDAD

POR DAÑOS

AMBIENTALES

THE DEATH

THROES OF THE

OLD SPANISH

SYSTEM OF

LIABILITY FOR

ENVIRONMENTAL

DAMAGE 
como ocurría también, por ejemplo, en el caso de daños ambientales causados por la propia administración, cuya reparación, si no cabía articularla en el marco de un procedimiento sancionador, era inexigible por la vía de la responsabilidad patrimonial de las administraciones públicas, que, digna heredera de la civil extracontractual, requiere un daño «individualizado con relación a una persona o grupo de personas» (artículo 139.2 LRJPAC).Y esto (el doble rechazo de una pretensión por inviabilidad de los cauces elegidos para su ejercicio), quizás no equivalga sin más a una denegación de justicia, a un auténtico conflicto negativo de competencia.

No obstante, posiblemente con más razón, nuestros tribunales no lo han visto así. Siguiendo ciertamente el propio planteamiento de la Junta y de los tribunales de lo contencioso-administrativo, la Sala Especial de Conflictos de Competencia del Tribunal Supremo ha decidido devolver el asunto a manos de la jurisdicción civil, por entender, sin duda de forma razonable, que la falta de potestad de autotutela por parte de la administración no equivale (no debe equivaler) a falta de fundamento de la pretensión, sino que implica tan solo la necesidad de acudir a la heterotutela (por parte de los tribunales civiles) para obtener su satisfacción, pero sin reparar en (o quizás en desacuerdo con) la jurisprudencia civil que antes hemos comentado.

Difícil tesitura, en todo caso, para el Juzgado de Primera Instancia número once de Sevilla, que, según informaciones de prensa, en diciembre de 2012 aún no había decidido sobre la admisión a trámite de la demanda. Si se mantiene en esta jurisprudencia, habrá de desestimarla, aunque tal vez cupiera discriminar, dentro de los gastos soportados por la Junta, los motivados por la expropiación de terrenos para la construcción del Corredor Verde del Guadiamar, y tratarlos como daños civiles tradicionales, susceptibles de una acción de reembolso, en la medida en que vinieron a compensar los perjuicios patrimoniales sufridos por los propietarios de las márgenes (algunos de los cuales, dicho sea de paso, consideraron insuficiente la reparación, y accionaron contra el Estado y la Junta en concepto de responsabilidad patrimonial, viendo rechazadas sus pretensiones, en otra de las numerosas líneas de litigio que ha generado el caso Boliden; ver, por ejemplo, entre otras, la sentencia de la Sala de lo Contencioso-Administrativo del Tribunal Supremo de 21 de abril de 2010 31 ).

Pero si, teniendo en cuenta la justicia intrínseca del caso y el agravio comparativo con la administración del Estado (aspectos estos sin duda latentes en todo momento en el planteamiento y devenir 
del conflicto de competencia), la jurisdicción civil decidiera, en esta segunda oportunidad, estimar la demanda, corrigiendo la jurisprudencia tradicional al respecto, se trataría sin duda de un hito, que, sin embargo, tal vez llegaría un poco tarde y quedara probablemente como un caso único y singular. Esto último puesto que, en adelante, no solo la Ley de Responsabilidad Medioambiental, sino también la propia directiva de la que trae causa, obligan a canalizar las pretensiones de reparación del daño ambiental propiamente dicho por la vía administrativa, sin perjuicio de que la reparación de los daños tradicionales en vía civil pueda conllevar en ocasiones la reparación total o parcial del propio daño ambiental, cosa que obviamente no queda excluida (artículo 5 y disposición adicional novena de la ley).

No hay que perder de vista, en cualquier caso, que con todo ello se trata únicamente de constituir un título que legitime la posición acreedora de la Junta, en las mismas condiciones que ya obtuvo en su día la administración estatal, pues el cobro efectivo de las cantidades reclamadas (o de parte de ellas) se está dilucidando en el procedimiento concursal (concurso voluntario de acreedores número 25/2005 de la entidad mercantil Boliden Apirsa, S.L.), que continúa tramitándose en estos momentos por el Juzgado de lo Mercantil número uno de Sevilla.

En fin, el caso Boliden, con toda su importancia objetiva y su enorme interés jurídico, pertenece al pasado. Si en la actualidad se produjera un suceso de similares características, bajo la nueva legislación, la administración competente (probablemente la Junta) abriría un expediente dirigido única y exclusivamente a depurar, con patrones objetivos, la responsabilidad medioambiental (en este caso, el recuperación del coste soportado por todas las administraciones que hubieran intervenido directamente en la reparación del daño), y la fijaría con carácter ejecutivo, con total y absoluta independencia de cualesquier otros procedimientos de carácter sancionador (penales o administrativos) o civiles (reparación de daños tradicionales). Ciertamente, el riesgo de insolvencia (y, por lo tanto, de falta de cobro) seguiría existiendo en tanto no se imponga a las actividades de riesgo, sujetas a un régimen de responsabilidad objetiva, la constitución de las garantías financieras obligatorias previstas por la ley, lo que de momento, con carácter general y en particular para la actividad aquí implicada, se ha demorado hasta el periodo 2016-2019 (por medio de la orden ARM/1783/2011, de 22 de junio ${ }^{32}$ ).

32 Orden ARM/1783/2011, de 22 de junio, por la que se establece el orden de prioridad y el calendario para la aprobación de las órdenes ministeriales a partir de las cuales será exigible la constitución de la garantía financiera obligatoria, previstas en la disposición final cuarta de la ley 26/2007, de 23 de octubre, de Responsabilidad Medioambiental.

LOS ÚLTIMOS

COLETAZOS DEL

VIEJO SISTEMA

ESPAÑOL DE

RESPONSABILIDAD

POR DAÑOS

AMBIENTALES

\section{THE DEATH}

THROES OF THE

OLD SPANISH

SYSTEM OF

LIABILITY FOR

ENVIRONMENTAL

DAMAGE 
Comenzamos esta tribuna señalando que, paradójicamente, poco se sabe todavía de la aplicación práctica de la nueva legislación y de su saludable régimen, aquí y en el conjunto de la Unión Europea. No obstante, antes del 30 de abril de 2014, la Comisión ha de presentar al Parlamento Europeo y al Consejo un informe sobre la experiencia adquirida en la aplicación de la directiva, que incluya en su caso las oportunas propuestas de modificación, basado lógicamente en los informes nacionales que, a su vez, los Estados miembros le han de presentar antes del 30 de abril de 2013 (artículo 18 de la directiva). Será de gran interés disponer de esta información, para la que afortunadamente no falta tanto tiempo. 